Relations industrielles

Industrial Relations

\title{
Psychology of Industrial Relations, C.H. LAWSHE, New York, McGraw- Hill Book Company, Inc., 1953, 350 pp.
}

\section{Guy Rocher}

Volume 10, numéro 2, mars 1955

URI : https://id.erudit.org/iderudit/1022748ar

DOI : https://doi.org/10.7202/1022748ar

Aller au sommaire du numéro

Éditeur(s)

Département des relations industrielles de l’Université Laval

ISSN

0034-379X (imprimé)

1703-8138 (numérique)

Découvrir la revue

Citer ce compte rendu

Rocher, G. (1955). Compte rendu de [Psychology of Industrial Relations, C.H.

LAWSHE, New York, McGraw- Hill Book Company, Inc., 1953, 350 pp.] Relations industrielles / Industrial Relations, 10(2), 139-139.

https://doi.org/10.7202/1022748ar

Tous droits réservés @ Département des relations industrielles de l’Université Laval, 1955
Ce document est protégé par la loi sur le droit d'auteur. L'utilisation des services d'Érudit (y compris la reproduction) est assujettie à sa politique d'utilisation que vous pouvez consulter en ligne.

https://apropos.erudit.org/fr/usagers/politique-dutilisation/ 
analysés dans un cadre qui facilite des rappels de théorie administrative. Enfin, $\mathrm{ar}_{2}$ effort est tenté dans le but de comparer non seulement la théorie à la pratique mais la pratique «proposée» à celle efficacement «réalisée».

En bref, cette étude d'un problème particulier d'administration permet certaines considérations qui le transcende, rejoint les cadres d'une théorie administrative et tente de mesurer l'ajio entre ce que l'on croit faire et ce qui est fait.

\section{JACQUES ST-LAURENT}

\section{Psychology of Industrial Relations,} C.H. LAwshe, New York, McGrawHill Book Company, Inc., 1953, $350 \mathrm{pp}$.

Ce volume ne présente pas le résultat d'une recherche originale dans le domaine de la psychologie industrielle. Il ne s'adresse pas d'abord aux psychologues et aux psychotechniciens. Son intention est tout autre. L'anteur qui est professeur de psychologie à Purdue University a déjà publié plusieurs étu des de psvchologie industrielle et destine son volume aux employeurs, ou plus exactement à tous ceux que couvrent les termes anglais «management and stipervision 》. Il évite, en conséquence, le iargon psychologique inutile et les problèmes encore mal éclairés; il recherche plutôt un langage clair, simple, à la portée d'un non initié à la terminologie et aux discussions de la psychologie.

Comme le: titre lui-même l'indique, le but poursuivi par lauteur consiste à éclairer un certain nombre de problèmes industriels à la lumière de la psychologie moderne. C'est ainsi que l'auteur considère certains aspects des relations entre le «management " t les travailleurs: l'embauchage et le placement du personnel, la réception des griefs. l'efficacité du travail des ouvriers, létablisscment d'un réseau de \& communications » efficace aux différents paliers, les relations avec les unions ouvrières, etc. Toutes ces questions sont considérées du point de vue de l'employeur, et des connaissances psychologiques dont il a besoin pour comprendre et juger sainement - et avec véri- té - le comportement et l'attitude des ouvriers qu'il dirige, et pour établir avec eux des relations plus harmonieuses et plus productives. A cette fin, le volume débute par deux chapitres où l'au teur cherche à dégager, en termes simples et nets, les principaux traits de la psychologie de louvrier, les sources de sa motivation en même temps que de son insatisfaction au travail. Le seul chapitre 3 ( \&otivation and Discontent in Industry $\gg)$ mériterait d'être lu par tous les employeurs, qu'il aiderait sans doute à comprendre sthe need for learning what the employee thinks $\gg$. (p. 55 ).

J'avone avoir été indisposé dès les premières pages: lauteur semblait mettre la psvchologie industrielle à la remorque de la seule productivité, tentation à laquelle la psychologie industrielle en général a plutôt mal échappé. Mais cette impression a été bientôt corrigée par la lecture des pages suivantes: lensemble du volume manifeste une préoccupation de l'ouvrier pour luimême, comme personne humaine et comme personnalité psychique. Que l'on me comprenne: je n'en ai évidemment pas contre la préoccupation aue l'on peut avoir d'une productivité industrielle nlus grande et surtout améliorée. Mais ic mopnose à ce que la psychologie industrielle ne soit envisagée que dans cette nerspective. Le but de la psvchologie industrielle - comme de toute ka psychologie - consiste d'abord et avant tout à comprendre l'activité humaine, les motifs qu'elle recouvre. les buts conscients th inconscients qu'elle poursuit. Ce n'est qu'envisagée de la sorte qu'une pswcholoqie peut être réaliste, et qu'elle est ensuite en mesure d'apporter à Pindustriel des solutions concrètes aux problèmes multiples qu'il rencontre.

Ajoutons enfin que lauteur a cherché à appuyer ses avancés sur les études et les enquêtes les plus récentes en psychologie industrielle. Le lecteur trouvera à la fin de chaque chapitre une liste imposante de références à des articles ou des volumes mentionnés dans le tcxte. Te souligne cependant le fait que ces références manifestent que lauteur connaît à veu près seulement la littérature américaine sur le suiet: il semble ignorer totalement les études réalisées en France et il utilise très peu les études anglaises.

Guy Rocher 